\title{
Inhibition of Folate Enzymes by Sulfasalazine
}

\author{
Jacob Selhub, G. Jeelani Dhar, and Irwin H. Rosenberg, Section of \\ Gastroenterology, Department of Medicine, The University of \\ Chicago, Pritzker School of Medicine, Chicago, Illinois 60637
}

\begin{abstract}
A B S T R A C T Sulfasalazine (salicylazosulfapyridine), an agent widely used for the treatment of ileitis and colitis, is also a competitive inhibitor of intestinal folate transport $(1,2)$. The mechanism of action of sulfasalazine remains uncertain. To further explore the mechanism of sulfasalazine action, the interaction of the drug with the folate recognition site was tested with three enzymes: dihydrofolate reductase, methylenetetrahydrofolate reductase, and serine transhydroxymethylase, each catalyzing a reaction involving a different folate derivative. Each of these enzymes was inhibited by sulfasalazine in the same concentration range as that previously observed to inhibit intestinal folate transport; the kinetic data are consistent with a competitive mode of inhibition. Specificity of inhibition was demonstrated by the finding that the reduction of the pteridine ring of pteroylheptaglutamic acid by dihydrofolate reductase was subject to inhibition, whereas the hydrolysis of the $\gamma$-glutamyl peptide side chain by chicken pancreas conjugase was not affected. These results are interpreted to indicate that sulfasalazine interferes with a folate recognition site which is common to these enzymes and to the intestinal transport system. Sulfasalazine, therefore, has certain properties of an antifolate drug.
\end{abstract}

\section{INTRODUCTION}

Sulfasalazine, commonly employed in the treatment of inflammatory bowel disease, is composed of sulfapyridine and 5-aminosalicylate linked through an azo

G. Jeelani Dhar was the recipient of the Daland Fellowship of the American Philosophical Society.

Received for publication 6 September 1977 and in revised form 17 October 1977. bond (Fig. 1). There is no convincing structural similarity between this compound and folic acid. Yet earlier data from this laboratory $(1,2)$ has shown that sulfasalazine is a competitive inhibitor of folate transport by the intestine. Sulfapyridine or 5-aminosalicylate, singly or in combination, were without effect.

Inasmuch as the intestinal transport process is shared by all folate derivatives tested $(2,3)$, it was assumed that sulfasalazine blocks a site that is responsible for the binding of folate analogues irrespective of the state of oxidation and one carbon substitution.

This assumption predicts that sulfasalazine may interact with similar sites on folate enzymes. To test this prediction, three enzymes, each catalyzing a reaction of different folate substrate, were tested for inhibition by sulfasalazine.

\section{METHODS}

Radioactive compounds. $\quad\left[{ }^{3} \mathrm{H}\right]$ Pteroylglutamic acid $(34 \mathrm{Ci} /$ $\mu \mathrm{mol}),\left[{ }^{14} \mathrm{CH}_{3}\right] N_{5}$-methyltetrahydrofolate $(53 \mu \mathrm{Ci} / \mu \mathrm{mol})$, and $\mathrm{L}-\left[3-{ }^{14} \mathrm{C}\right]$ serine $(60 \mu \mathrm{Ci} / \mu \mathrm{mol})$ were purchased from Amersham/Searle Corp. (Arlington Heights, Ill.); $\left[{ }^{3} \mathrm{H}\right]$ pteroylheptaglutamate $(132 \mu \mathrm{Ci} / \mu \mathrm{mol})$ was prepared by the procedure described by Godwin et al. (4). Tetrahydrofolate was prepared from folic acid by reduction with sodium dithionite (5) and purification on a DEAE-cellulose column (6). This compound was stored in evacuated vials in a refrigerator (7).

Dihydrofolate reductase was prepared from rat liver as described by Peterson et al. (8) with the exception of the affinity chromatography step. The enzyme was assayed by the method of Rothenberg (9) except for $\left[{ }^{3} \mathrm{H}\right]$ pteroylglutamic acid and NADPH concentrations, which were increased to 5 and $50 \mu \mathrm{M}$, respectively. For study of $\left[{ }^{3} \mathrm{H}\right]$ pteroylheptaglutamate reduction, the substrate concentration was $1 \mu \mathrm{M}$ and the $\mathrm{ZnSO}_{4}$ concentration required for coprecipitation of the unreduced substrate with unlabeled folic acid (9) was increased to $0.35 \mathrm{M}$.

Methylenetetrahydrofolate reductase and serine transhy- 

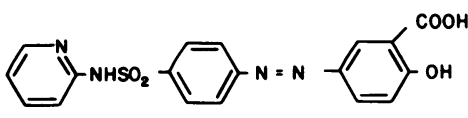

SULFASALAZINE

SULFAPYRIDINE

5-AMNOSALICYLIC

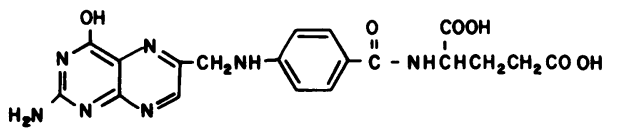

FOLIC ACID

Figure 1 Chemical formulas of sulfasalazine and folic acid.

droxymethylase were prepared from rat liver by homogenization in four volumes of water and precipitation with ammonium sulfate at $55 \%$ saturation (10). The first enzyme was assayed in its reverse reaction by the method described by Kutzbach and Stokstad (11). Serine transhydroxymethylase was assayed by the extent of methylenetetrahydrofolate formation from $\mathrm{L}-\left[3-{ }^{14} \mathrm{C}\right]$ serine and tetrahydrofolate (12).

Chicken pancreas conjugase was prepared from the acetone powder (Difco Laboratories, Detroit, Mich.) as described by Eigen and Shockman (13). Activity was determined by the extent of the hydrolysis of $1 \mu \mathrm{mol}$ of $\left[{ }^{3} \mathrm{H}\right]$ pteroylheptaglutamate at $\mathrm{pH} 7.0$ after $10 \mathrm{~min}$ incubation at $37^{\circ} \mathrm{C}$. The product of the reaction was determined by Lactobacillus casei (ATCC 7469) uptake after $10 \mathrm{~min}$ incubation (14).

Enzyme activities were determined after incubation at $37^{\circ} \mathrm{C}$ for $10 \mathrm{~min}$ except for methylenetetrahydrofolate reductase which was incubated at $32^{\circ} \mathrm{C}$ for $10 \mathrm{~min}$. Sulfasalazine (Pharmacia Fine Chemicals, Uppsala, Sweden) was dissolved by heating in a boiling water bath with $0.005 \mathrm{M}$ potassium phosphate buffer, $\mathrm{pH}$ 7.0. It was added to the reaction mixtures before the addition of the enzyme solutions. None of the procedures employed for determination of reaction product was affected by this compound.

\section{RESULTS}

Sulfasalazine inhibited each of the three enzymes tested in a dose-dependent fashion as shown in Fig. 2. Of the three, methylene-tetrahydrofolate reductase was the most sensitive to inhibition. Under identical assay conditions dihydrofolate reductase was not inhibited by the metabolites of sulfasalazine, sulfapyridine, and 5 -amino salicylate, either alone or in combination.

The kinetic analysis shown in Fig. 3 indicates that sulfasalazine competed specifically with the folate substrates. When tested against varying concentrations of the corresponding folate substrates of each of the three enzymes, the drug affected the $K_{m}$ but not the $\mathrm{V}_{\max }$ of the reactions. Sulfasalazine did not compete with nonfolate substrates such as serine by serine transhydroxymethylase (Fig. $3 \mathrm{~d}$ ). When tested against changing serine concentrations at constant concentration of tetrahydrofolate, sulfasalazine affected the $V_{\max }$, not the $K_{m}$, which is consistent with the noncompetitive mode of inhibition at the serine binding site.

The affinity constants of substrates and inhibitor of the three enzymes and the intestinal folate transport system are given in Table 1.

In the preceeding experiments sulfasalazine was tested against enzymes, each employing a different monoglutamyl folate derivative as a substrate. In this experiment the inhibitor was tested for its effectiveness against enzymes which act on different sites of the same substrate. Reduction of the pteridine ring of pteroylheptaglutamate by dihydrofolate reductase was inhibited (Fig. 4) whereas sulfasalazine had no effect on the hydrolysis of the $\gamma$-glutamyl peptide chain by chicken pancreas conjugase.

\section{DISCUSSION}

Three enzymes, each with a specific folate substrate, were inhibited by sulfasalazine, and the inhibition was competitive with respect to the folate substrate with inhibition constants within one order of magnitude (Table I). Dihydrofolate reductase reduced both monoglutamyl and heptaglutamyl folate, and sulfasalazine was inhibitory in both systems. We have shown previously that the intestinal transport of folic acid and $N_{5}$-methyltetrahydrofolate were both equally inhibited by sulfasalazine (2). This suggests that the folate binding sites of these enzymes and the folate intestinal transport system possess common structural features that are independent of the state of oxidation,

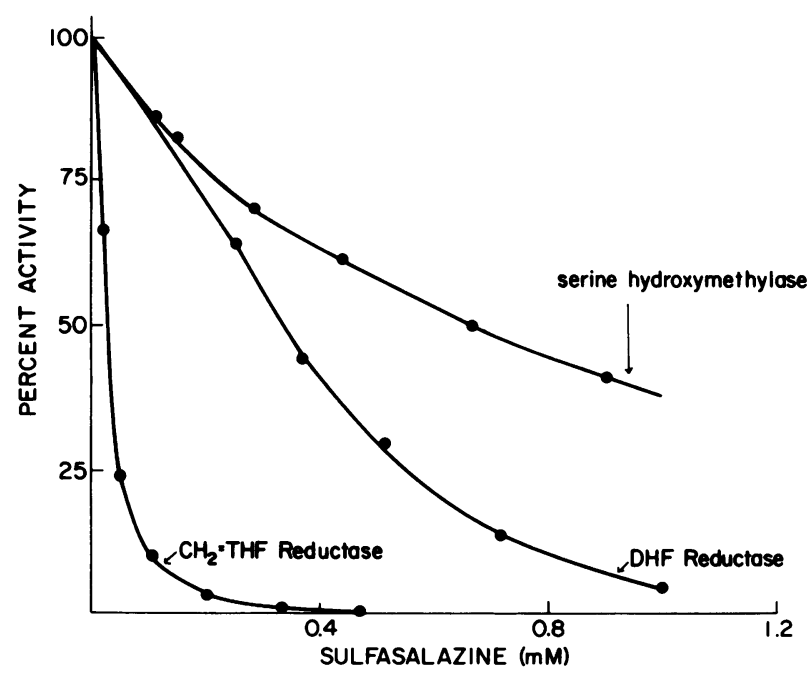

FIGURE 2 Effect of increasing sulfasalazine concentration on the activities of folate enzymes. Methylenetetrahydrofolate reductase ( $1 \mathrm{mg}$ protein), dihydrofolate reductase (1 $\mathrm{mg}$ protein), and serine transhydroxymethylase $(0.24 \mathrm{mg}$ protein) were incubated with their respective substrates, under conditions described in Methods with increasing concentrations of sulfasalazine. The effect of the drug is expressed as percent of enzyme activity without sulfasalazine. Actual amount of product ( $100 \%$ of control activity) was 9.1, 2.2, and $29.2 \mathrm{nmol}$, respectively, for the three enzymes. 

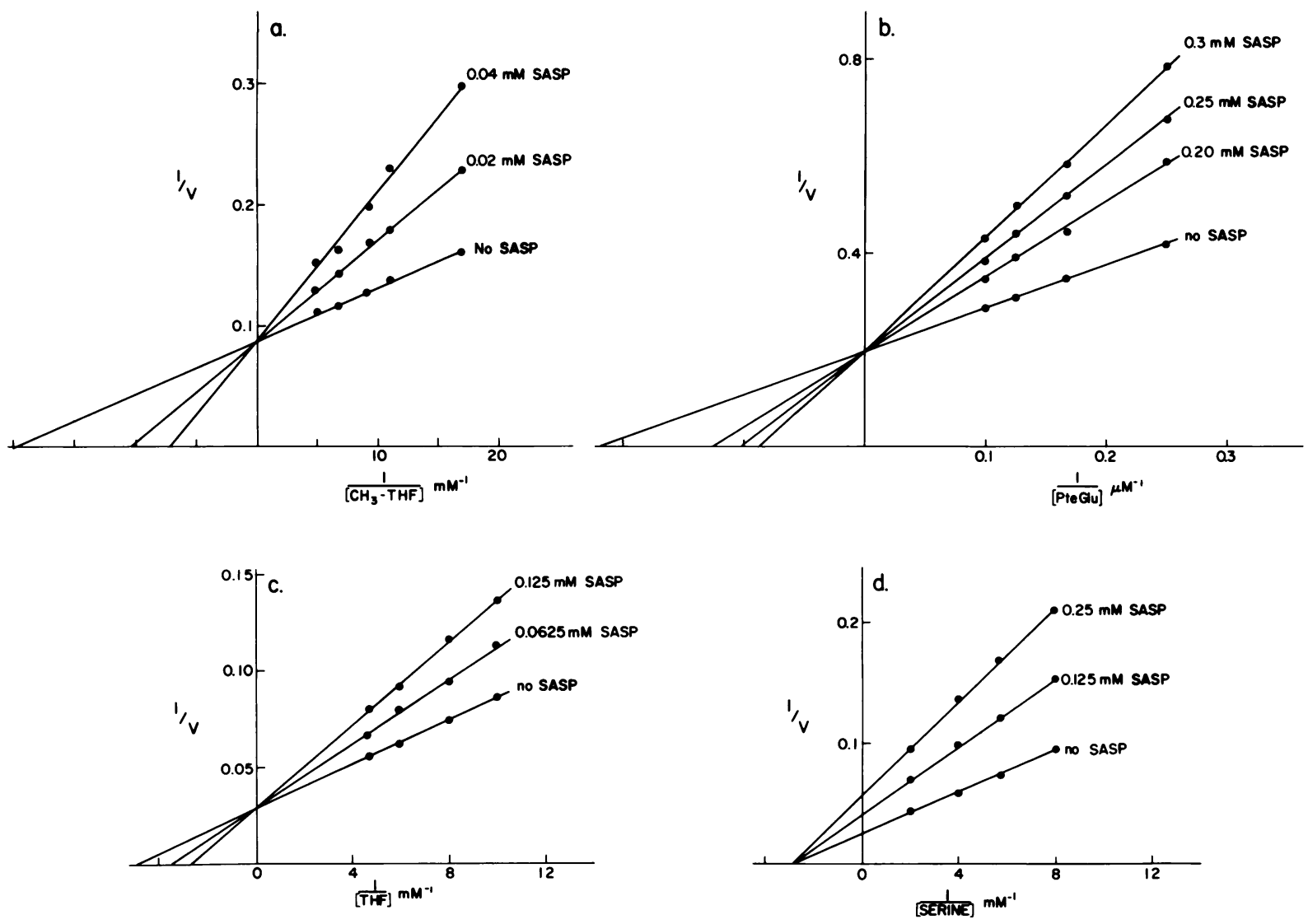

FIGURE 3 Lineweaver-Burk plots of the inhibition of folate enzymes by sulfasalazine (SASP): (a) methylenetetrahydrofolate reductase (0.96 $\mathrm{mg}$ protein); (b) dihydrofolate reductase (1 mg protein); (c) serine transhydroxymethylase $(0.12 \mathrm{mg}$ protein) at changing tetrahydrofolate concentrations and constant amount of L-serine $(0.5 \mathrm{mM}) ;(\mathrm{d})$ serine transhydroxymethylase $(0.12$ $\mathrm{mg}$ protein) at changing serine concentrations and constant amount of tetrahydrofolate $(0.2 \mathrm{mM})$. The velocities are expressed in nanomoles of product formed per incubation. Similar ordinate intercepts indicate a competitive mode of inhibition. Noncompetitive inhibition is depicted by similar abscissa intercepts.

methyl group substitution, or the presence of extra glutamic acid residue on the folate molecules.

According to current concepts summarized by Blakley (15), dihydrofolate reductase possesses three distinct binding regions: an ionizable region that binds the $p$-carboxyl group by charge transfer, a hydrophobic region that binds a moiety located four to eight atoms away from the $p$-carboxyl group toward the pteridine ring, and a third region that is weakly acidic and interacts with the basic groups of the pyrimidine ring. It is possible that sulfasalazine possesses the proper structure for recognition by these regions. The carboxyl group of salicylic acid is a potential moiety for recognition by the first region. The basic nitrogen on the pyridine ring could recognize the third region whereas the benzene ring could be the primary target for the binding by the hydrophobic region. Further studies employing various derivatives of sulfasalazine
TABLE I

Summary of the Kinetic Constants

\begin{tabular}{lcc}
\hline \multicolumn{1}{c}{ System } & Apparent $K_{m}$ & Apparent $K_{i}$ \\
\hline $\begin{array}{l}\text { Folate transport* } \\
\text { Dihydrofolate } \\
\text { reductase }\end{array}$ & 0.004 PteGlu & $\mathrm{mM}$ sulfasalazine \\
$\begin{array}{l}\text { Methylenetetra- } \\
\text { hydrofolate } \\
\text { reductase }\end{array}$ & 0.004 PteGlu & 0.09 \\
$\begin{array}{l}\text { Serine hydroxy- } \\
\text { methylase }\end{array}$ & 0.100 1-tetrahydrofolate & 0.23 \\
\hline
\end{tabular}

* From Dhar et al. (2).

$\$$ Pteroylglutamic acid. 


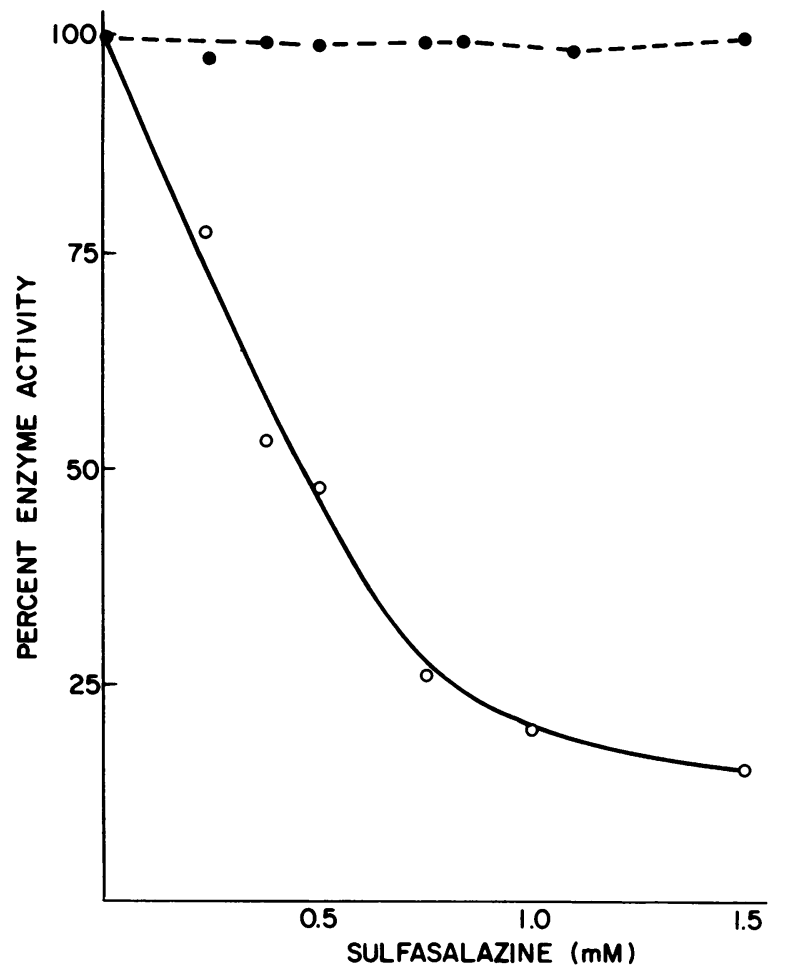

FIGURE 4 Effect of sulfasalazine on the enzymatic reduction and hydrolysis of $\left[{ }^{3} \mathrm{H}\right]$ Pteroylheptaglutamate. The substrate was incubated under conditions described in Methods with dihydrofolate reductase $(0.35 \mathrm{mg}$ protein, solid line) or chicken pancreas conjugase ( $0.06 \mathrm{mg}$ protein, dashed line) with and without increasing concentrations of sulfasalazine. Activities obtained were plotted as percentage of control incubations without sulfasalazine $(0.866 \mathrm{nmol}$ of substrate reduced and $0.236 \mathrm{nmol}$ of substrate hydrolyzed).

will be required to confirm these possibilities. Sulfasalazine and its derivatives should be useful in probing the structural requirements for binding of folate substrates to enzymes and transport systems.

The pharmacological implications of these observations are uncertain. The mechanism of action of sulfasalazine in ileitis and colitis remains controversial (16). Current concepts emphasize the importance of bacterial lysis of the azo linkage with local release of 5 -aminosalicylate and the sulfa moiety in the intestine $(17,18)$. However, $10-15 \%$ of sulfasalazine is absorbed intact in the proximal intestine (16-18), and the possibility that the parent molecule, not its catabolites, is active as an inflammatory suppressant has not been excluded. On the basis of the enzyme inhibition reported here, sulfasalazine acts as a weak antifolate drug. As such, it could suppress proliferation of inflammatory cells or of epithelial cells turning over rapidly. Because both types of cell proliferation are elements in the pathogenesis of colitis, this hypothesis deserves further assessment.

\section{ACKNOWLEDGMENTS}

This work was supported by grant AM-15351 from the National Institutes of Health.

\section{REFERENCES}

1. Franklin, J. L., and I. H. Rosenberg. 1973. Impaired folic acid absorption in inflammatory bowel disease: effects of salicylazosulfapyridine (Azulfidine). Gastroenterology. 64: 517-525.

2. Dhar, G. J., J. Selhub, and I. Rosenberg. 1976. Azulfidine inhibition of folic acid absorption: confirmation of a specific saturable transport mechanism. Gastroenterology. 70: 878A. (Abstr.)

3. Rosenberg, I. H. 1976. Absorption and malabsorption of folates. Clinics in Haematology. 5: 589-617.

4. Godwin, H. A., I. H. Rosenberg, C. S. Ferenz, P. M. Jacobs, and J. Meienhofer. 1972. The synthesis of biologically active pteroyloligo- $\gamma$-L-glutamates (folic acid conjugates). J. Biol. Chem. 8: 2266-2271.

5. Davis, L. 1968. A simple method for the synthesis of tetrahydrofolic acid. Anal. Biochem. 26: 459-460.

6. Selhub, J., H. Brin, and N. Grossowicz. 1973. Uptake and reduction of radioactive folate by everted sacs of rat small intestine. Eur. J. Biochem. 33: 433-438.

7. Ritari, S. J., W. Sakami, C. W. Black, and J. A. Rzepka. 1975. The determination of folylpolyglutamate synthetase. Anal. Biochem. 63: 118-129.

8. Peterson, D. L., J. M. Gleisner, and R. L. Blakley. 1975. Bovine liver dihydrofolate reductase: purification and properties of the enzyme. Biochemistry. 14: 52615267.

9. Rothenberg, S. P. 1966. A rapid radioassay for folic acid reductase and amethopterin. Anal. Biochem. 16: 176179.

10. Buchanan, J. M. 1971. Methionine biosynthesis (hog liver). Methods Enzymol. 17: 371-378.

11. Kutzbach, C., and E. L. R. Stokstad. 1967. Feedback inhibition of methylenetetrahydrofolate reductase in rat liver by $S$-adenosylmethionine. Biochim. Biophys. Acta. 139: $217-220$.

12. Taylor, R. T., and H. Weissbach. 1965. Radioactive assay for serine transhydroxymethylase. Anal. Biochem. 13: $80-84$.

13. Eigen, E., and G. D. Shockman. 1963. The folic acid group. In Analytic Microbiology. F. Kavanagh, editor. Academic Press, Inc., New York 431-488.

14. Shane, B., and E. L. R. Stokstad. 1975. Transport and metabolism of folates by bacteria. J. Biol. Chem. 250: 2243-2253.

15. Blakley, R. L. 1969. The biological reduction of pteridines. In The Biochemistry of Folic Acid and Related Pteridines. A. Neuberger and E. L. Tatum, editors. North-Holland Publishing Company, Amsterdam-London. 162-187.

16. Goldman, P., and M. A. Peppercorn. 1975. Drug therapysulfasalazine. N. Engl. J. Med. 293: 20-23.

17. Peppercorn, M. A., and P. Goldman. 1972. The role of intestinal bacteria in the metabolism of salicylazosulfapyridine. J. Pharmacol. Exp. Ther. 181: 555-561.

18. Schröder, H., and D. F. S. Campbell. 1972. Absorption, metabolism and excretion of salicylazosulfapyridine in man. Clin. Pharmacol Ther. 13: 539-551. 